\title{
The passage of protozoa from the reticulo-rumen through the omasum of sheep
}

\author{
BY T. MICHALOWSKI*, J. HARMEYER † AND G. BREVES \\ Department of Physiology, School of Veterinary Medicine, Bischofsholer Damm 15, \\ 3000 Hannover, Federal Republic of Germany
}

(Received 4 July 1985 - Accepted 16 June 1986)

\begin{abstract}
1. Protozoa in rumen contents and omasal effluent of growing wethers were counted. The wethers were equipped with rumen and abomasal cannulas, and omasal sleeves attached to the omasal-abomasal orifice. Rumen fluid dilution rates were elevated by continuous infusions of hypertonic mineral solutions (3-4 litres/d) for $24 \mathrm{~d}$. Rumen contents and omasal effluent were sampled between 9 and $21 \mathrm{~h}$ during the last $10 \mathrm{~d}$ of each experiment.

2. Protozoal concentrations in omasal effluent were only $0 \cdot 2-0 \cdot 3$ those found in the rumen under normal conditions. The ratio of protozoal concentrations in rumen : those in omasal effluent was for small Diplodinium spp. 4.6 (SD 0.9), for Ophryoscolex spp. 4.3 (SD 1.0), for Dasytricha ruminantium 4.0 (SD 0.5), for Isotricha spp. 3.8 (SD 0.8), for Entodinium spp. 3.6 (SD 0.9) and for Polyplastron multivesiculatum 2.6 (SD 0.5).

3. Elevation of rumen fluid dilution rate by 20 and $55 \%$ respectively, increased protozoal concentrations in omasal effluents from 22 to $33 \%$ and from 31 to $47 \%$ those in rumen contents. The apparent residence times of protozoa in the rumen were decreased $50 \%$ by the infusion of a mineral-salt solution. The increase in rumen fluid dilution rate had no significant effect on concentrations of protozoa in the rumen or on the differences of the apparent residence times between different species. The apparent residence time of holotrichs remained the same before and after infusion of the mineral-salt solution.

4. Apparent residence times of individual species of protozoa in the rumen were, under normal feeding conditions, $2.55 \mathrm{~d}$, and were four to six times longer than the mean residence time of CrEDTA in the rumen.
\end{abstract}

Experiments with cattle and sheep indicate that rumen protozoa do not emerge from the omasum in proportion to their concentration in the rumen. Weller \& Pilgrim (1974), using sheep fed on various roughage diets, reported that the concentration ratio of protozoa:CrEDTA in digesta from the omasal canal was usually less than $20 \%$ that in strained rumen fluid. Harrison et al. (1979) calculated that the rate of flow of protozoal nitrogen at the duodenum was only $41 \%$ that calculated from the rumen fluid dilution rate.

Evidence of a selective retention of mainly large rumen ciliates in cattle, principally Isotricha spp., was obtained by Leng et al. (1981), who introduced ${ }^{14} \mathrm{C}$-labelled holotrichs into the rumen of three Zebu bulls. The rate of disappearance of radioactivity of labelled protozoa was found to be much slower than predicted from the dilution rate of rumen fluid.

However, samples obtained from the omasal canal may not be representative of rumen effluent. Thus concentration differences of protozoa may not provide conclusive evidence for selective retention of protozoa in the rumen. Most particles usually pass between the leaves of the omasum rather than through the omasal canal. Estimates of protozoal flow obtained from ${ }^{35} \mathrm{~S}$ incorporation (Harrison et al. 1979), or from diaminopimelic acid concentrations in rumen contents and duodenal digesta, are usually indirect and are obtained by difference.

We have attempted to measure protozoal outflow directly from the omasum and to count the number of protozoa which pass into the abomasum. In addition, outflow of individual protozoal species in the digestive contents of the rumen were counted and attempts were made to study the effect of changes in rumen dilution rate on outflow of individual species.

\footnotetext{
* Present address: Department of Animal Physiology, University of Warsaw, 02-089 Warszawa, Zwirki i Wigury 93 , Poland.

$\dagger$ For reprints: Institute of Physiology, School of Veterinary Medicine, Bischofsholer Damm 15, 3000 Hannover, Federal Republic of Germany.
} 


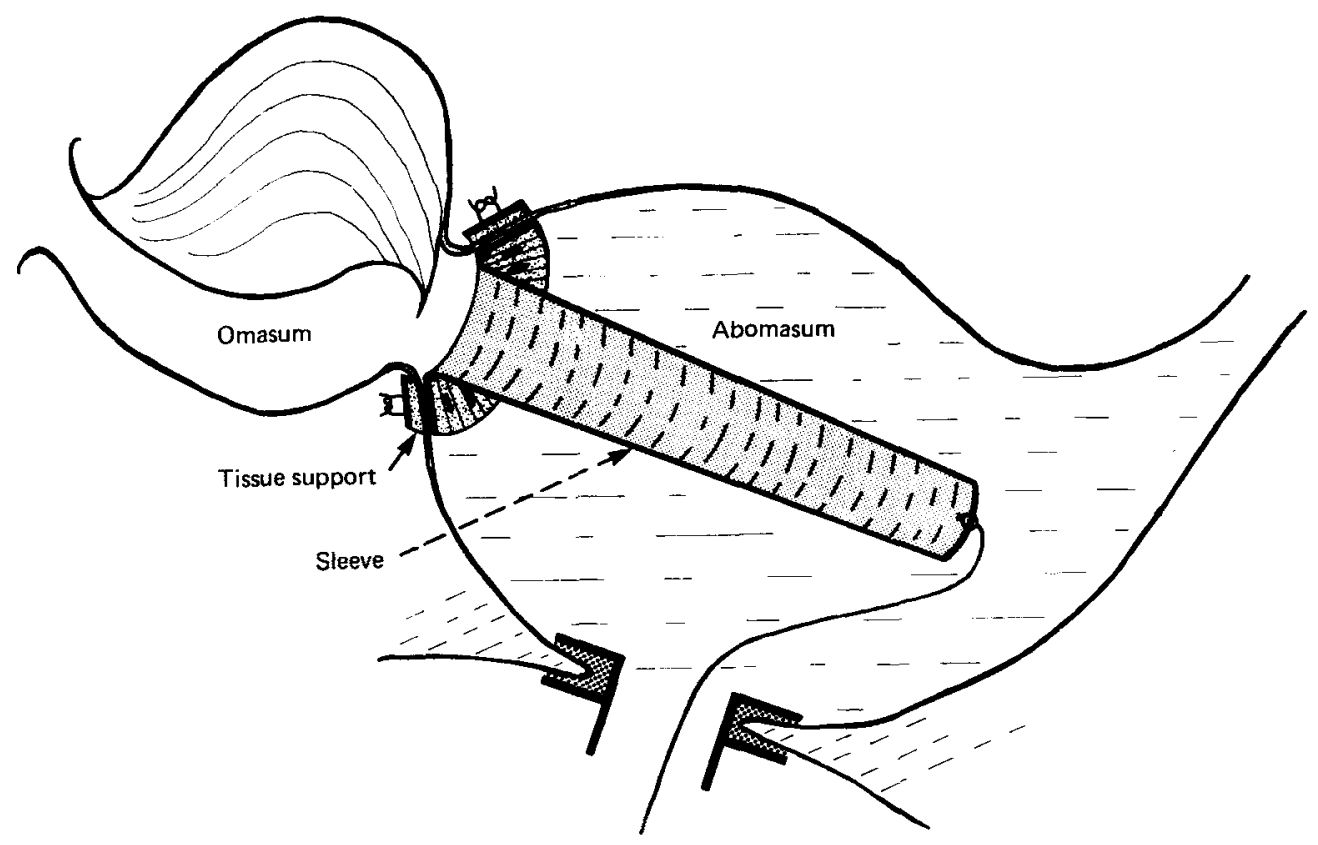

Fig. 1. Schematic representation of an omasal sleeve, which was fixed at the omasal-abomasal orifice. The collar of the rubber sleeve was fixed around the omasal-abomasal orifice by about twelve individually fastened knots. The knots are located outside the abomasum over a synthetic tissue support (Prosthex Medilab; Düsseldorf, Federal Republic of Germany).

\section{MATERIAL AND METHODS}

\section{Animals and feeding}

Six sheep were used for the experiments. Three growing sheep (nos. 2, 4, 5), 9-11 months old, $30-40 \mathrm{~kg}$ live weight, were used for collection of omasal effluents. The animals were kept in separate pens and given approximately $600 \mathrm{~g}$ hay $(95 \mathrm{~g}$ crude protein (CP; $\mathrm{N} \times 6.25)$ ) and $700 \mathrm{~g}$ concentrate $(185 \mathrm{~g} \mathrm{CP} / \mathrm{kg}$ ) per $\mathrm{d}$ in equal quantities at 9.00 and 21.00 hours. Daily intake of digestible energy was approximately $14.7 \mathrm{MJ}$. Water was available at all times. The animals were given the experimental diet at least 4 weeks before the experimental period started.

Three mature wethers (A, B, C), provided with rumen fistulas and weighing $70-75 \mathrm{~kg}$, were used for counting protozoal concentrations at various sites of the reticulo-rumen. The animals were kept together in one pen and were given the hay-concentrate diet at maintenance level $(700 \mathrm{~g}$ hay and $500 \mathrm{~g}$ concentrate/d). Access to water was also allowed at all times.

\section{Surgery}

Animals (nos. 2, 4 and 5) were fitted with permanent rumen ( $30 \mathrm{~mm}$ outside diameter (o.d.)) and abomasal ( $40 \mathrm{~mm}$ o.d.) cannulas. For collection of omasal effluent, nylon-texture rubber sleeves $(300 \mathrm{~mm})$ were sutured to the omasal-abomasal orifice following a modified procedure of Engelhardt \& Hauffe (1975) (Fig. 1). Animals A, B and C were equipped with a $120 \mathrm{~mm}$ rumen fistula which provided access by hand to reticulo-rumen contents. 
Table 1. Composition ( $\mathrm{mmol} / \mathrm{l})$ of the mineral salt solution continuously infused into the rumen for $24 d$ at a rate of 3-4 litres $/ d$

\begin{tabular}{lr}
\hline $\mathrm{NaHCO}_{3}$ & $125 \cdot 0$ \\
$\mathrm{Na}_{2} \mathrm{HPO}_{4}$ & $20 \cdot 4$ \\
$\mathrm{KH}_{2} \mathrm{PO}_{4}$ & $30 \cdot 1$ \\
$\mathrm{NaCl}$ & $35 \cdot 9$ \\
$\mathrm{Na}_{2} \mathrm{SO}_{4} \cdot 10 \mathrm{H}_{2} \mathrm{O}$ & $3 \cdot 5$ \\
$\mathrm{CaCl}_{2} \cdot 2 \mathrm{H}_{2} \mathrm{O}$ & $0 \cdot 7$ \\
$\mathrm{MgCl}_{2}$ & $1 \cdot 3$ \\
\hline
\end{tabular}

Table 2. Sampling procedure: during the preliminary period $(14 d)$ only rumen contents were sampled, during the experimental period $(10 \mathrm{~d})$ both rumen contents and omasal effluent were sampled

\begin{tabular}{lcccc}
\hline & $\begin{array}{c}\text { Day of } \\
\text { experiment }\end{array}$ & $\begin{array}{c}\text { Sampling } \\
\text { interval (h) }\end{array}$ & $\begin{array}{c}\text { No. of } \\
\text { samples (/d) }\end{array}$ & $\begin{array}{c}\text { Index } \\
\text { examined }\end{array}$ \\
\hline Preliminary period & 1 & 2 & 8 & \\
& $2-3$ & 6 & 3 & CrEDTA \\
Experimental period & $4-14$ & 12 & 2 & $\begin{array}{c}\text { CrEDTA, } \\
\text { protozoa, } \\
\text { dry matter }\end{array}$ \\
\hline
\end{tabular}

\section{Experimental procedures}

Five infusion experiments were carried out with three sheep. In three experiments, deionized water was continuously infused into the rumen of sheep nos. 2, 4 and 5 at the rate of $500-600 \mathrm{ml} / \mathrm{d}$ (treatment A). In two experiments a hyperosmotic salt solution was infused into the rumen of sheep nos. 2 and 4 (treatment $B$ ) in order to increase rumen dilution rate. All experiments consisted of a $14 \mathrm{~d}$ preliminary period and a $10 \mathrm{~d}$ experimental period. During treatment $A$ the infusate contained $1.03-1.07 \mathrm{mg}$ chromium $/ \mathrm{ml}$ as CrEDTA and was infused at a rate of $21.4-24.0 \mathrm{mg} \mathrm{Cr} / \mathrm{h}$. During treatment $\mathrm{B}$ the hyperosmotic salt solutions (Table 1) contained 0.13 and $0.18 \mathrm{mg} \mathrm{Cr} / \mathrm{ml}$ as CrEDTA. The solutions were infused at a rate of $21.4 \mathrm{mg} \mathrm{Cr} / \mathrm{h}$ (sheep no. 2) and $22.3 \mathrm{mg} \mathrm{Cr} / \mathrm{h}$ (sheep no. 4) which corresponded to daily volumes of infusion of 4 and 3 litres respectively.

Samples of rumen contents were collected during the preliminary period and during the experimental period at different time intervals (Table 2). Omasal effluent was only sampled during the experimental period (Table 2). Samples for protozoa counts and for dry matter (DM) determinations in rumen contents and omasal effluent were taken on days 3, 5 and 8 of the experimental period. Sampling times were at 9.00 hours (before morning feeding), $10.00,14.00,17.00$ and 21.00 hours (before the evening feeding). Samples for CrEDTA measurements were taken from the rumen during both the preliminary and experimental periods and from omasal effluent only during the experimental periods.

Approximately $300 \mathrm{~g}$ rumen contents were collected from different sites of the rumen. The samples were obtained by suction via a $25 \mathrm{~mm}$ internal diameter (i.d.) plastic tube. Rumen samples were of a pasty consistency and contained food particles over $10 \mathrm{~mm}$ in length. After thorough mixing, samples for protozoa counts $(5 \mathrm{~g})$, for the determination of DM (25 g), and for CrEDTA in rumen fluid (about $20 \mathrm{~g}$ ) were taken. The 
remaining material was returned to the rumen. Omasal effluent $(10-50 \mathrm{~g})$ was collected from the sleeve via the abomasal cannula. Samples of omasal effluent were taken for protozoal counts (2-5 g), and for the determination of DM (5-25 g) and CrEDTA (3-10 g). Remaining effluent, if any, was returned to the rumen, together with some abomasal contents which flowed through the abomasal fistula while it was open.

In sheep A, B, and C, protozoal concentrations were counted in whole rumen contents, in rumen fluid and in reticular contents. For comparison of rumen contents and rumen fluid and for comparison of rumen contents and reticular contents samples were collected on different days $4 \mathrm{~h}$ after the morning feed. Rumen contents were sampled by inserting a hand through the fistula and collecting material from the caudal rumen. Reticular contents were obtained by suction via a $15 \mathrm{~mm}$ i.d. plastic tube. Rumen fluid was obtained by squeezing rumen contents through four layers of gauze. All the samples were diluted in equal volumes of a $40 \mathrm{ml}$ formaldehyde/1 solution in preparation for counting protozoa.

\section{Counting of protozoa}

The ciliates from the genus Entodinium, small Diplodinium spp. and Dasytricha ruminantium were counted in a Fuchs-Rosenthal counting chamber (500-2500 cells were counted per sample and per species). Large ciliates (Isotricha and Ophryoscolex spp. and Polyplastron multivesiculatum) were counted (approximately 500-1000 cells per sample per species) by a method described previously (Michalowski, 1975). Different Entodinium spp. were not identified. The small Diplodinia contained mainly Eudiplodinium (Diploplastron) affine, less Anoplodinium (Diplodinium) denticulatum and Ostracodinium triloricatum. The Ophryoscolex spp. were mainly $O$. caudatus.

\section{Analyses}

DM of rumen contents and omasal effluent were determined by weighing before and after freeze-drying for $36 \mathrm{~h}$. Cr was estimated in rumen fluid and omasal effluent by atomic absorption spectrometry (Perkin Elmer 400) using $36000 \mathrm{~g}$ supernatant fractions. Osmolality of rumen fluids and of omasal effluent was determined by freezing point depression.

\section{Calculations}

At the start of the CrEDTA infusion, rumen fluid samples were collected at intervals of $1-4 \mathrm{~h}$. Rumen fluid volumes and rumen fluid dilution rates were calculated from the CrEDTA concentration $v$, time-interval curves. The values obtained at the beginning of the infusion were fitted by a computer program to a function of the form $C=A\left(1-\mathrm{e}^{-k t}\right)$ where $C$ is CrEDTA concentration $(\mathrm{mg} / \mathrm{kg}$ ) (Harmeyer \& Reinhardt, 1973); $A$ is plateau concentration $(\mathrm{mg} / \mathrm{kg})$, i.e. $A=I /(V . k)$ where $k$ is dilution rate $(1 / \mathrm{d}), I$ is rate of infusion $(\mathrm{mg} / \mathrm{d})$ and $V$ is rumen volume $(\mathrm{kg})$, and $t$ is time $(\mathrm{d})$.

The fluid outflow rate was then calculated from the equation: $I / A=V \cdot k(\mathrm{~kg} / \mathrm{d})$. Flow $(F)$ of DM in omasal effluent was calculated from the equation:

$$
F(\mathrm{~kg} / \mathrm{d})=\frac{\text { DM in omasal effluent } \times I}{\text { CrEDTA in omasal effluent }} .
$$

Omasal flow of fluid $(\mathrm{kg} / \mathrm{d})$ was calculated from the rate of infusion of CrEDTA $(I)$ and the concentration of CrEDTA in omasal effluent during steady-state conditions. Apparent residence time $(T ; \mathrm{d})$ of protozoa in the rumen was calculated from individual rumen and omasal samples from the following equation:

$$
T(\mathrm{~d})=\frac{\text { rumen volume } \times \text { protozoal concentration in rumen }}{\text { protozoal concentration in omasal effluent } \times \text { omasal flow }} .
$$


This is the time-interval which elapses when a quantity of protozoa flows out of the omasum equivalent to the amount present in the rumen (apparent turnover time). The apparent turnover time of the rumen fluid-phase was calculated from the rate constant of CrEDTA: $T^{\prime}(\mathrm{d})=1 / k$.

\section{Statistics}

Indices of rumen function, omasal effluent and protozoal concentrations were statistically treated by analysis of variance. A four-factorial ANOVA was used for several indices of rumen contents and omasal effuent of animals 2 and 4 . The four factors were (1) treatment, (2) animals, (3) days of experiment, (4) time of sampling. Another four-factorial ANOVA was used for analysis of mean residence times of protozoa in animals 2 and 4 using the factors (1) protozoal species, (2) treatment, (3) animals, (4) day of experiment. A third four-factorial ANOVA was used for analysis of protozoal residence times in animals 2 and 4 with factors (1) protozoal species, (2) treatment, (3) animals, (4) time of sampling. A three-factorial ANOVA was used for animals 2, 4 and 5 using values from treatment A. Differences of protozoal concentrations between rumen contents and omasal effluent were tested for significance using the $t$ test (Winer, 1971; Weber, 1972).

\section{RESULTS}

\section{Sequestration of protozoa in the rumen}

Protozoal counts carried out on contents from the rumen and from the reticulum of sheep A, B and C showed that numbers of Entodinium, small Diplodinium and Dasytricha spp. were nearly the same in both of these compartments (Table 3). Concentrations of Polyplastron multivesiculatum, Ophryoscolex caudatus and Isotricha spp. were, however, $20-50 \%$ less in reticular contents compared with the caudal rumen.

Protozoa were also enumerated in strained rumen fluid and rumen contents. Concentrations of different species were $\left(\times 10^{4}\right)$ : for Entodinium spp. 60 (SD 20) and 61 (SD 22), for small Diplodinium spp. 1.7 (SD 1.2) and 2.7 (SD 1.6), for Polyplastron multivesiculatum 0.2 (SD 0.07) and 0.4 (SD 0.007), for Ophryoscolex spp. 0.2 and $0.6(n 1)$, for Dasytricha ruminantium 1.2 (SD 0.5) and 1.1 (SD 0.5), and for Isotricha spp. 0.5 (SD 0.3) and 1.0 (SD $0 \cdot 5)$ in rumen fluid and rumen contents respectively.

\section{Concentrations of protozoa in rumen contents and in omasal effluent}

Mean concentrations of ciliates in rumen contents and in omasal effluent, and apparent residence times of protozoa in the rumen from animals 2,4 and 5 during infusion of water (treatment A) are shown in Table 4. Ophryoscolex spp. were only present in animals 2 and 4 , and Dasytricha ruminantium was only present in animals 2 and 5. Total protozoal concentrations and concentrations of individual species in omasal effluent were approximately $25 \%$ of the respective concentrations in rumen contents. Concentration of all species in omasal effluent was significantly lower than that in the rumen contents $(P<0 \cdot 001)$. Apparent residence times in the rumen were between 1.9 and $3.0 \mathrm{~d}$ and differed significantly between species (Table 4). The turnover time of CrEDTA was 0.54 (SD 0.02) $\mathrm{d}$ and was significantly lower than the apparent turnover times of protozoa $(P<0.001)$. Results of statistical comparison of the means of the protozoal concentrations in the rumen between animals, between days of experiment and between different times of sampling are included in Table 4. The same comparison was made for the concentrations of protozoa in the omasal effluent and for the apparent residence times of protozoa in the rumen (Table 4). 
Table 3. Concentrations of protozoa $\left(\times 10^{3} / \mathrm{g}\right)$ in rumen and reticular contents of three mature sheep fed at maintenance

(Mean values and standard deviations for three determinations)

\begin{tabular}{|c|c|c|c|c|}
\hline \multirow[b]{2}{*}{ Protozoa } & \multicolumn{2}{|c|}{ Rumen } & \multicolumn{2}{|c|}{ Reticulum } \\
\hline & Mean & SD & Mean & SD \\
\hline & \multicolumn{4}{|c|}{ Sheep A } \\
\hline Entodinium spp. & 519 & 44 & 538 & 51 \\
\hline Small Diplodinium spp. & $10 \cdot 5$ & $7 \cdot 52$ & $11 \cdot 2$ & $5 \cdot 04$ \\
\hline Polyplastron multivesiculatum & 0.8 & 0.43 & 0.5 & 0.26 \\
\hline Ophryoscolex spp. & - & - & - & - \\
\hline Isotricha spp. & $1 \cdot 6$ & $0 \cdot 36$ & 0.6 & 0.32 \\
\hline Dasytricha ruminantium & $6 \cdot 8$ & $3 \cdot 0$ & $8 \cdot 1$ & 3.9 \\
\hline \multirow[t]{2}{*}{ Total } & 539 & 34 & 559 & 37 \\
\hline & \multicolumn{4}{|c|}{ Sheep B } \\
\hline Entodinium spp. & 297 & 31 & 289 & 31 \\
\hline Small Diplodinium spp. & $14 \cdot 6$ & $2 \cdot 6$ & $10 \cdot 1$ & $2 \cdot 4$ \\
\hline Polyplastron multivesiculatum & $1 \cdot 7$ & 0.40 & $1 \cdot 3$ & 0.5 \\
\hline Ophryoscolex spp. & $1 \cdot 8$ & 0.88 & $1 \cdot 3$ & 0.38 \\
\hline Isotricha spp. & $5 \cdot 7$ & 1.6 & 3.9 & $1 \cdot 5$ \\
\hline Dasytricha ruminantium & 21 & $3 \cdot 5$ & 21 & $7 \cdot 6$ \\
\hline \multirow[t]{2}{*}{ Total } & 342 & 29 & 326 & 35 \\
\hline & \multicolumn{4}{|c|}{ Sheep C } \\
\hline Entodinium spp. & 419 & 11 & 423 & 20 \\
\hline Small Diplodinium spp. & $27 \cdot 5$ & $5 \cdot 1$ & $26 \cdot 3$ & $3 \cdot 8$ \\
\hline Polyplastron multivesiculatum & $3 \cdot 1$ & 0.87 & 1.9 & 0.49 \\
\hline Ophryoscolex spp. & $9 \cdot 2$ & $1 \cdot 5$ & $4 \cdot 4$ & $2 \cdot 7$ \\
\hline Isotricha spp. & $16 \cdot 1$ & $4 \cdot 3$ & $8 \cdot 1$ & $3 \cdot 7$ \\
\hline Dasytricha ruminantium & 48 & 11 & 47 & $6 \cdot 1$ \\
\hline Total & 523 & 21 & 511 & $4 \cdot 7$ \\
\hline
\end{tabular}

\section{Effect of an infusion of mineral-salt solution on rumen volume and osmotic pressure of rumen fluid}

The volume and osmotic pressure of rumen fluid, osmotic pressures of omasal effluent and the daily omasal flow in sheep nos. 2 and 4 during infusion of water and mineral-salt solution are shown in Table 5. Osmotic pressure in the rumen was significantly elevated by 28 mosmol/ 1 by infusion of the mineral-salt solution. It differed also between animals and was affected by the day of experiment and by the time of sampling $(P<0.01$; Table 5). Osmotic pressure in the rumen was at a maximum $2 \mathrm{~h}$ after feeding. Omasal flow was also significantly affected by the treatment, the time of sampling and differed between the two animals. Interaction of treatment-animal for daily omasal flow was also significant due to the fact that omasal flow increased with the infusion of salt solution in animal no. 2 but not in animal no. 4. Rumen and omasal osmotic pressures were significantly higher in sheep no. 4 during mineral-salt infusion (312 and $238 \mathrm{mosmol} / \mathrm{l}$ respectively) than in sheep no. 2 (233 and $205 \mathrm{mosmol} / \mathrm{l}$ respectively). Osmotic pressure differences between rumen contents and omasal effluent were largest $2 \mathrm{~h}$ after feeding. The small decrease of rumen volume due to the infusion of salt was not significant. The mean $\mathrm{pH}$ in the rumen was unaffected by the hypertonic load but varied significantly with time-interval after feeding. Rumen fluid 
Protozoa in rumen and omasal effluent

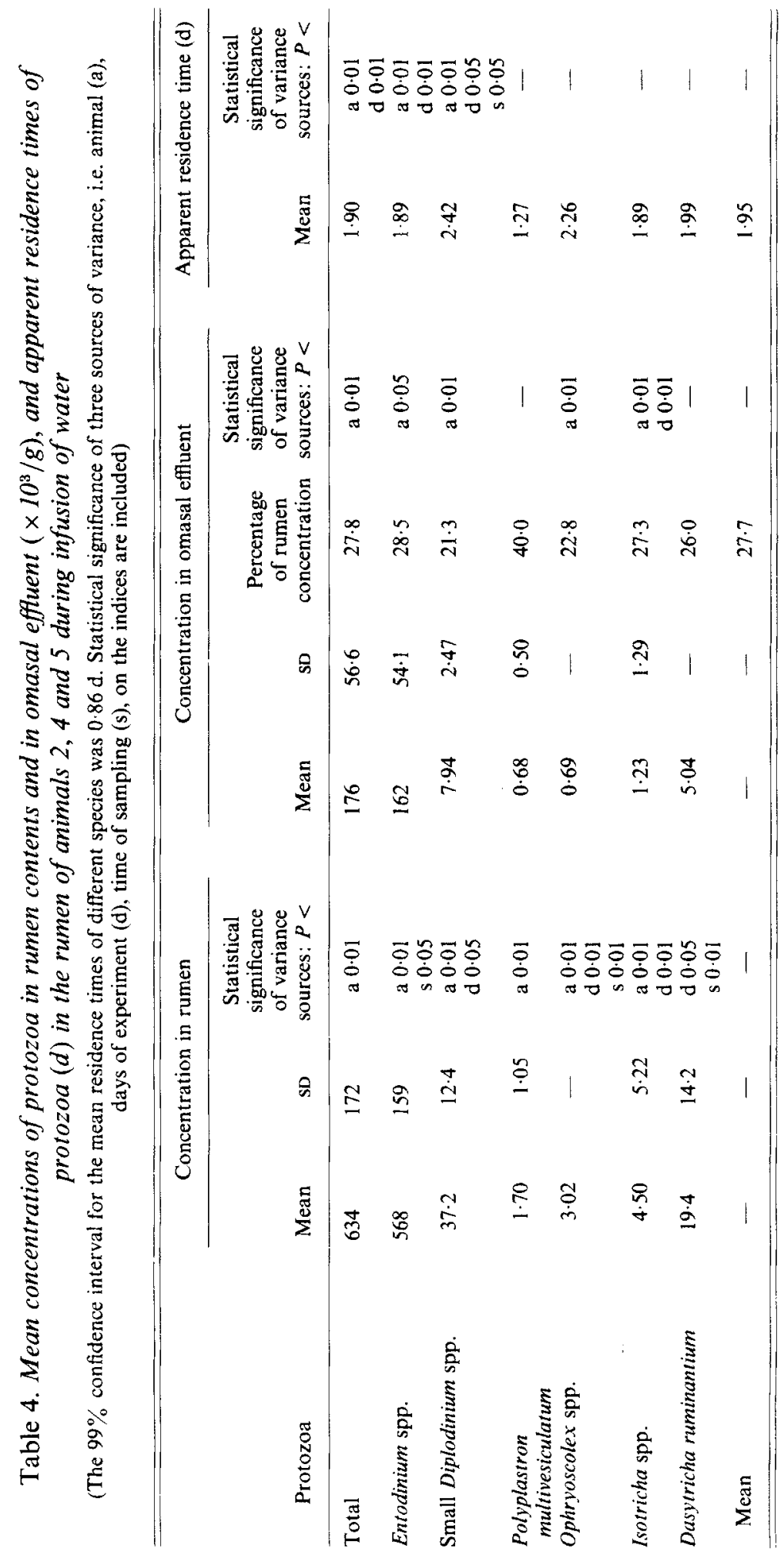




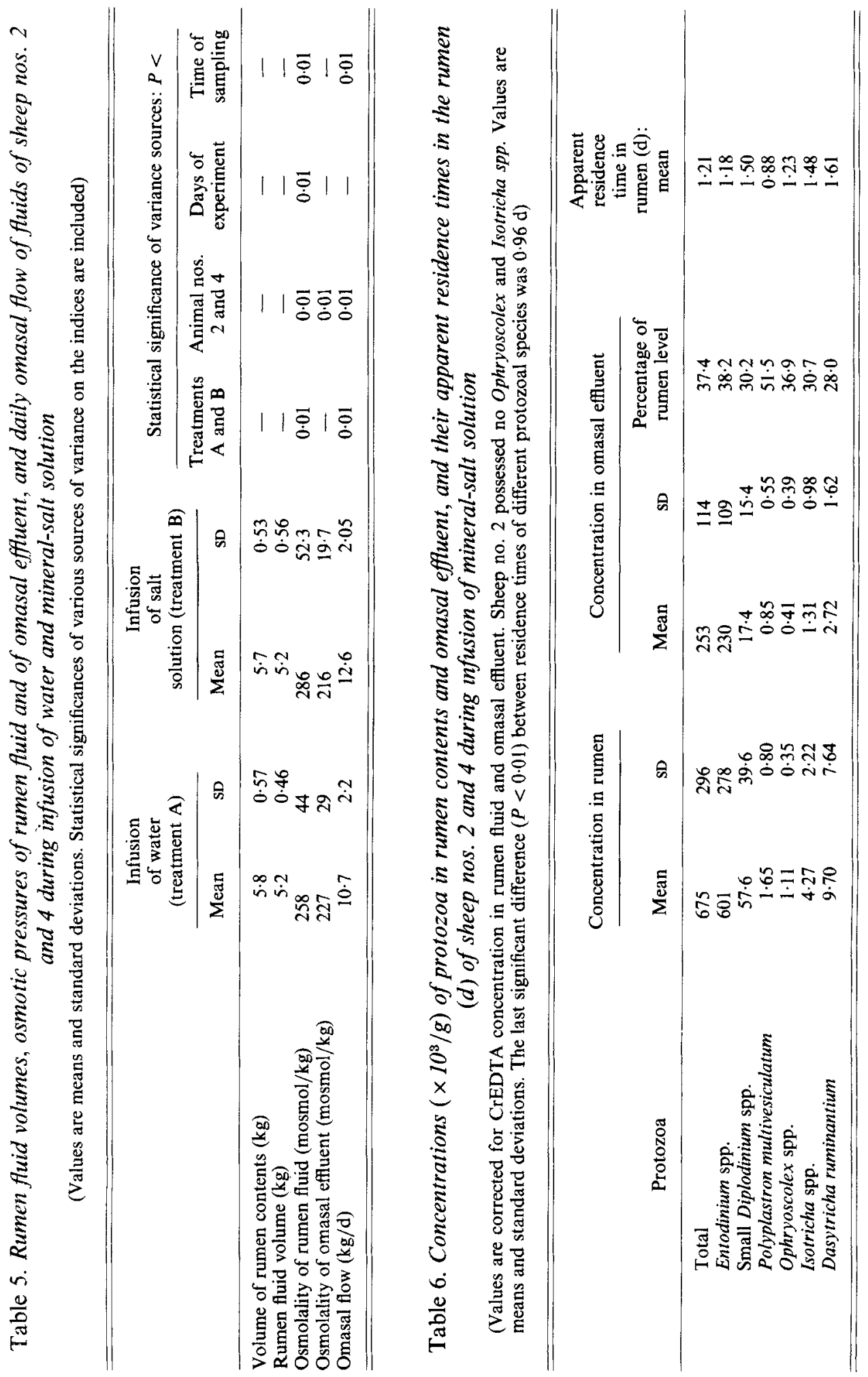


dilution rates (/d) increased in sheep no. 2 from 1.76 (SD 0.17) to 2.73 (SD 0.54) and in sheep no. 4 from 1.63 (SD 0.15 ) to 1.95 (SD 0.28 ) through the infusion of salt solution.

\section{Effect of an infusion of salts on the concentrations of protozoa in the rumen and in the omasal effluents}

Mean concentrations of protozoa in the rumen and in omasal effluents, and apparent residence times of ciliates in animals 2 and 4 during treatment B are shown in Table 6 . Infusion of a hypertonic solution reduced the apparent residence times of protozoa in the rumen significantly $(P<0.001)$. Differences in the residence times between protozoal species during treatments $\mathrm{A}$ and $\mathrm{B}$ were not significant. The ranking of apparent residence times between individual species remained similar under normal conditions and during the osmotic load. The concentration ratio of protozoa in omasal effluent:rumen contents (corrected for the CrEDTA concentrations) increased from 0.22 to 0.31 (sheep no. 2) and from 0.33 to 0.47 (sheep no. 4). This corresponded to a decrease in apparent residence times from $2 \cdot 1$ to $1.3 \mathrm{~d}$ (sheep no. 2) and from 2.0 to $1 \cdot 2 \mathrm{~d}$ (sheep no. 4). Outflow of holotrichs, however, appeared to be less affected by imposing the hypertonic load (Tables 4 and 6). Finally, no correlation was seen between rumen: omasal effluent osmotic pressure differences and rumen: omasal effluent protozoal concentration differences.

\section{DISCUSSION}

The results presented provide direct evidence for a reduced concentration of protozoa in omasal effluent compared with rumen contents of sheep. The extent to which protozoa were selectively retained in the rumen or disappear during passage through the omasum differed somewhat with protozoal species and varied with the physical conditions present in the rumen. The concentration difference between the rumen contents and omasal effluent was in general less for Polyplastron multivesiculatum than for the smaller species (entodinia and small diplodinia).

The factors responsible for the difference in protozoal concentration between rumen contents and omasal effluent are not entirely clear. It results, at least partly, from sequestration in the solid phase of the rumen. It is also possible that selective retention and lysis of protozoa occurs in the omasum, which may contribute to the concentration difference of protozoa between rumen contents and omasal effluent.

Some observations indicate that protozoal lysis may occur in the omasum. Leng (1982) introduced $\left[{ }^{14} \mathrm{C}\right]$ choline-labelled protozoa into the rumen of sheep. Of the ${ }^{14} \mathrm{Clabel}, 50-70 \%$ was irreversibly lost from the protozoal fraction and was recovered from rumen methane. Leng (1982) concluded that the radioactivity in methane resulted from degradation of protozoa in the rumen. Part of the ${ }^{14} \mathrm{CH}_{4}$ release could have occurred, however, in the omasum. Studies by Steinhour et al. (1982) also presented indirect evidence that outflow of protozoa from the rumen is higher than could be deduced from concentration differences between rumen contents and omasal effluent. Using a kinetic program, Steinhour et al. (1982) calculated the proportion of duodenal $\mathrm{N}$ incorporated in protozoa. The proportion was $0.22-0.41$ of the ammonia- $\mathrm{N}$ incorporated into microbial matter.

\section{Effect of a hypertonic load}

Infusion of a hypertonic solution into the rumen elevated the rumen fluid dilution rate without changing the rumen fluid volume significantly. This was consistent with observations by Harrison et al. (1979) from similar experiments. However, in contrast to their findings the hypertonic load in the present experiments did not lower protozoal concen- 
trations in the rumen. The absence of a correlation between rumen osmolality and the concentration of holotrichs in the rumen of sheep was also reported by Dehority \& Males (1974). In fact, protozoal concentrations tended to increase in those experiments which showed an increase in rumen osmolality. In our experiments there were, however, marked fluctuations of the total protozoal concentration, irrespective of the infusion of salt solution. Outflow of holotrichs was also little affected by the increase in rumen fluid dilution rate in our experiment. This may be related to the ability of the holotrichs to adhere to the rumen wall, thereby finding protection from wash-out (Abe et al. 1981).

Our findings show, by direct measurement, that protozoa do not enter the omasum at the same rate as the fluid marker, CrEDTA. The role the omasum plays in this context remains to be elucidated, particularly as to whether significant lysis of protozoa occurs during passage through the omasum. If this was the case our findings indicate that lysis of small protozoal species in the omasum was greater than that of the larger species. Concentration differences between rumen contents and omasal effluent were always greater for the small protozoal species than for larger species.

The work was supported by the Alexander of Humboldt Foundation.

\section{REFERENCES}

Abe, M., Iriki, T., Tobe, N. \& Shibui, H. (1981). Applied Environmental Microbiology 41, 758-765.

Dehority, B. A. \& Males, J. R. (1974). Journal of Animal Science 38, 865-870.

Engelhardt, W. v. \& Hauffe, R. (1975). In Digestion and Metabolism in the Ruminant, pp. 216-230[I. W. McDonald and A. C. I. Warner, editors]. Armidale, New South Wales: University of New England Publishing Unit.

Harmeyer, J. \& Reinhardt, H. J. (1973). Archiv für Tierernährung 23, 475-478.

Harrison, D. G., Beever, D. E. \& Osbourn, D. F. (1979). British Journal of Nutrition 41, 521-527.

Leng, R. A. (1982). British Journal of Nutrition 48, 399-415.

Leng, R. A., Gill, M., Kempton, T. J., Rowe, B. J., Nolan, J. V., Stachiw, S. J. \& Preston, T. R. (1981). British Journal of Nutrition 46, 371-384.

Michalowski, T. (1975). Journal of Agricultural Science, Cambridge 85, 145-150.

Steinhour, W. D., Stokes, H. R., Clark, J. H., Rogers, J. A. \& Davis, C. L. (1982). British Journal of Nutrition 48, 417-431.

Weber, E. (1972). Grundriss der Biologischen Statistik, pp. 320-327. Stuttgart:Gustav Fischer Verlag.

Weller, R. A. \& Pilgrim, A. F. (1974). British Journal of Nutrition 32, 341-351.

Winer, B. J. (1971). Statistical Principles in Experimental Design, pp. 539-559. New York: McGraw Hill Kogakusha Ltd. 